\title{
Cennestato
}

\section{Competência em Informação e Mídia no Ensino de História: observações acerca de indicações de obras cinematográficas em meios virtuais}

\author{
Sabrina Simões Corrêa \\ Mestre; Universidade Federal do Rio Grande, Rio Grande, RS, Brasil; \\ sabrinascsc@gmail.com \\ Renata Braz Gonçalves \\ Doutora; Universidade Federal do Rio Grande, Rio Grande, RS, Brasil; \\ renatas.braz@gmail.com
}

\begin{abstract}
Resumo: A presente pesquisa objetivou relacionar dados coletados em blogs e sites administrados por professores de História da educação básica com os pressupostos teórico-conceituais da media information literacy a fim de discutir a abordagem dada aos recursos cinematográficos indicados nesses meios virtuais para fins didático-pedagógicos. Quanto à metodologia, esta pesquisa caracterizase como um estudo descritivo de cunho quali-quantitativo. A elaboração do estudo se deu através da pesquisa bibliográfica e da pesquisa documental, cujas fontes foram os meios virtuais. A análise foi pautada pelo método de Análise de Conteúdo. No que se refere aos resultados, a pesquisa observou 25 meios virtuais, dos quais nove apresentaram indicações de obras cinematográficas, totalizando 362 filmes distintos. As informações concedidas pelos docentes nos meios virtuais permitiram a identificação de aspectos voltados à competência em informação e mídia, dentre eles: menções relacionadas ao acesso, à avaliação e ao uso dos recursos fílmicos; apontamento de dados referentes à indicação de autoria nas informações postadas nos meios virtuais; observação de informações que admitissem o potencial democrático e positivo do uso das linguagens fílmicas para fins educacionais, bem como o potencial negativo, voltado à ideia de que há intenções comerciais e ideológicas por trás da produção cinematográfica. Conclui-se que é fundamental haver o aprimoramento e o desenvolvimento de habilidades e competências informacionais e midiáticas, uma vez que o acesso a recursos 'não convencionais' exige dos indivíduos novas habilidades. Nesse contexto, o bibliotecário se insere como agente mediador na promoção de estratégias para o uso efetivo e ético da informação.
\end{abstract}

Palavras-chave: Competência em Informação e Mídia. Ensino de História. Mídias na Educação. Cinema. 


\section{Introdução}

A utilização de blogs e outros recursos tecnológicos na educação já vem sendo discutida no campo do Ensino e da Ciência da Informação em virtude da ascensão das tecnologias de informação e comunicação (TICs) nos ambientes escolares e nas práticas cotidianas de indivíduos de diferentes faixas etárias e condições socioeconômicos (DUDZIAK; BELLUZZO, 2008; ZANCHETTA JUNIOR, 2017). O uso dessas mídias virtuais com intento educacional pode contribuir para o desenvolvimento de competências " [...] associadas à pesquisa e seleção de informação, à produção de texto escrito [e] ao domínio de diversos serviços e ferramentas.” (LOSSO; CRISTIANO; LUZ FILHO, 2011, p. 54).

Nas últimas décadas, cresceu a produção de blogs e sites administrados por professores. Na área de História, percebeu-se a criação e a utilização desses meios virtuais como apoio intra e extraclasse, no qual docentes fazem uso dessas ferramentas para retomar discussões acerca dos conteúdos ministrados em aula (LOSSO; CRISTIANO; LUZ FILHO, 2011) e, por vezes, dão indicações de filmes que interagem com esses conteúdos.

A presente pesquisa tem como objeto de estudo os blogs elaborados por professores de História brasileiros e se concentrou na abordagem, dada por esses blogs, ao uso de obras cinematográficas no/para o ensino. Parte-se do pressuposto de que as fontes exploradas para análise — as mídias virtuais (blogs ou sites), são recursos didático-pedagógicos e informacionais e, nesse sentido, devem ser entendidas como fontes de informação, assim como os recursos fílmicos indicados nesses meios virtuais.

Neste contexto, entende-se que a análise dos meios virtuais possibilitou a identificação de filmes cinematográficos que podem auxiliar na compreensão de assuntos relacionados à História, aplicados ou não à sala de aula.

No âmbito do acesso a fontes de informação, ressalta-se a importância de proporcionar ao público escolar (e ao público geral) o acesso democrático a recursos informacionais variados e, também, direcionamento para o uso efetivo desses recursos. Dessa forma, esta investigação se justifica pela contribuição que estabelece ao promover o diálogo entre agentes educacionais atuantes na 
Educação Básica (professores, bibliotecários, gestores), no que diz respeito ao acesso eficiente e ético a diferentes fontes de informação.

\section{Media information literacy e sua relação com as práticas de ensino- aprendizagem na disciplina História}

O presente tópico busca contextualizar os pressupostos teórico-conceituais da media information literacy com o Ensino de História, principalmente no que se refere às práticas didáticas docentes utilizando filmes cinematográficos. Neste contexto, abordam-se questões relacionadas ao conceito de Competência em Informação e Mídia (CIM) - expressão adotada nesta pesquisa como correlata a media information literacy, e sua implicação no uso efetivo de recursos de informação e midiáticos. Fundamenta-se na hipótese de que, para ensinar utilizando outros recursos ditos não tradicionais, é necessário que o professor tenha conhecimento e capacidade de manuseio eficiente e ético desses recursos (WILSON et al., 2013).

O tema tecnologia e educação já vem sendo explorado e discutido, em âmbito nacional e internacional, desde o fim do século XX e início do século XXI. A preocupação com o impacto que as mídias provocariam no contexto educacional era reflexo das diferentes gerações que coexistiam (e coexistem) nos ambientes escolares. Para os membros da chamada "Geração Internet", como observaram Tufte e Christensen (2009, p. 99), as mídias já se configuram parte central da vida - desde que tais crianças e jovens estejam em situação socioeconômica favorável para desfrutar desses recursos.

Porém, na escola, essas novas mídias ainda não haviam se estabelecido como parte integrante e cotidiana nos processos de ensino-aprendizagem. Um dos principais motivos para esse obstáculo era a "barreira entre gerações" (TUFTE; CHRISTENSEN, 2009, p. 100). Mesmo após uma década da publicação das considerações apresentadas por Tufte e Christensen (2009), a referida barreira ainda é percebida, como pode ser observada através das recentes publicações em âmbito do media information literacy (ou information literacy).

Nessa perspectiva, a Organização das Nações Unidas para a Educação, a Ciência e a Cultura (Unesco) vem se posicionando favorável e apoiadora ao uso 
de tecnologias e mídias em âmbito educacional e buscou, através da publicação de Padrões de competência em TIC para professores: diretrizes de implementação, versão 1.0 (UNESCO, 2009) e Alfabetização midiática e informacional: currículo para formação de professores (WILSON et al., 2013), evidenciar o papel e a importância dos educadores na construção de habilidades e competências voltadas ao uso de TICs. O manuseio desses recursos configura-se como uma importante ferramenta de acesso igualitário à informação e ao conhecimento. Sob essa ótica, estando os professores e demais educadores habilitados ao uso de mídias, a barreira entre gerações estaria fadada a desaparecer.

O manejo de recursos informacionais e midiáticos é um desafio que as escolas precisam aceitar e, nesse sentido, o professor pode cumprir papel de facilitador e treinador nesse processo de aprendizagem que se apoia numa variedade de fontes e recursos de informação, a fim de preparar o estudante para o mundo que o cerca (CARVALHO; GASQUE, 2018).

Via de regra, ter acesso à informação/tecnologia/mídia não significa que o sujeito irá explorá-la em sua totalidade, ou seja, transformá-la em “[...] conhecimento que possa se converter em vantagem, seja ela pessoal, competitiva ou organizacional.” (POZO, $2004^{1}$ apud CARVALHO; GASQUE, 2018, p. 108). Há a necessidade de capacitar as pessoas para lidar com a tecnologia/mídia (e com a informação contida nela) e desfrutar das possibilidades que ela proporciona. Assim, os profissionais responsáveis pelos processos de aprendizagem, em destaque os professores e bibliotecários, são imprescindíveis para a construção dessas competências (CARVALHO; GASQUE, 2018).

No entanto, os recursos midiáticos não foram pensados, a princípio, para exercer funções pedagógicas. Em virtude dessa característica, é necessário pensar em uma educação para mídia e informação (GRIZZLE et al., 2016), possibilitando que indivíduos de diferentes níveis escolares e faixa etárias desfrutem das possibilidades e vantagens exploradas por meio desses recursos.

Os pressupostos teórico-conceituais da media information literacy (expressão norte-americana) são abordados, aqui no Brasil, por diversos(as) pesquisadores(as), a exemplo: Carvalho e Gasque (2012), Dudziak e Belluzzo (2008), Vitorino e Piantola (2011), entre outros(as). Em âmbito internacional, nas 
últimas décadas, a temática passou a ser de interesse da UNESCO em virtude de sua relação com a formação pessoal e profissional dos indivíduos. O conceito de media information literacy é definido como a combinação de conhecimentos, atitudes, habilidades e práticas exigidas para acessar/recuperar, analisar, avaliar/questionar, usar, produzir/criar e compartilhar/comunicar informações e conteúdos midiáticos de forma criativa, efetiva e ética (GRIZZLE et al., 2016; MARCO..., 2016). Indivíduos alfabetizados em mídia e informação sabem de qual informação precisam e quando precisam dela, para qual finalidade (pessoais, profissionais e sociais), onde e como obtê-la (GRIZZLE et al., 2016).

O desenvolvimento de competências midiáticas e informacionais vai além das TICs e inclui habilidades de aprendizagem, pensamento crítico, interpretação, competências operacionais e comunicacionais que auxiliam no aprimoramento educacional, profissional e social de um indivíduo. Envolve todos os formatos de mídia (verbal, impressa, analógica e digital) e os mais diversos recursos e ferramentas (GRIZZLE et al., 2016).

O Quadro 1 apresenta a correspondência entre as dimensões da Competência em Informação (CoInfo) propostas por Vitorino e Piantola (2011) e os níveis/padrões de Competência em Informação e Mídia (CIM) apontados pela UNESCO (WILSON et al., 2013).

Quadro 1 - Dimensões da CoInfo e padrões de CIM

\begin{tabular}{|c|cl|}
\hline Dimensões & \multicolumn{1}{c|}{ Padrões/Indicadores } \\
\hline \multirow{2}{*}{ Técnica } & $\checkmark$ & Compreender os conteúdos das mídias e seus usos; \\
& $\checkmark$ & $\begin{array}{l}\text { Acessar do modo eficiente e eficaz a informação (em qualquer } \\
\text { formato/suporte); }\end{array}$ \\
& $\checkmark$ & Avaliar de modo crítico a informação e suas fontes. \\
\hline \multirow{2}{*}{ Estética } & $\checkmark$ & $\begin{array}{l}\text { Aplicar formatos novos e tradicionais de mídias em diferentes } \\
\text { situações. }\end{array}$ \\
\hline Ética & $\checkmark$ & $\begin{array}{l}\text { Utilizar a informação e a mídia de modo ético, respeitando os direitos } \\
\text { autorais e agindo com responsabilidade. }\end{array}$ \\
\hline \multirow{2}{*}{ Política } & $\checkmark$ & $\begin{array}{l}\text { Ter consciência do papel das mídias e da informação na democracia; } \\
\text { Situar-se no contexto sociocultural dos conteúdos midiáticos e de } \\
\text { produção. }\end{array}$ \\
\hline
\end{tabular}

Fonte: Adaptado de Vitorino e Piantola (2011) e Wilson e outros (2013).

O conjunto desses padrões e, consequentemente, dessas dimensões, se configura nas habilidades e nos saberes necessários para possibilitar ações que capacitam ou formam indivíduos competentes no uso eficiente e ético de informações e recursos midiáticos. Portanto, percebe-se a importância do desenvolvimento ou aprimoramento de competências em âmbito do uso da 
informação e das mídias. Há a necessidade, nesse sentido, de promover a ação de novas leituras nos processos de ensino-aprendizagem. A leitura não é prática exclusiva do texto, do papel, da escrita: lê-se o mundo, as coisas, os objetos, as pessoas etc. (SILVA, 2004).

Mediante estas considerações, faz-se necessário apontar questões voltadas ao uso de recursos fílmicos nos processos de ensino-aprendizagem e, consequentemente, às habilidades e competências que podem ser desenvolvidas ou aprimoradas através desses recursos. No âmbito do Ensino de História, em específico, Napolitano (2015) aponta que a utilização de filmes para tratar assuntos históricos (ou do campo das Humanidades) possibilita a noção de que há diferentes visões da História e auxilia na percepção de como os sujeitos do passado eram representados. Além disso, permite o desenvolvimento dos princípios da pesquisa histórica “[...] valendo-se da reconstituição e representação do passado nos filmes" (NAPOLITANO, 2015, p. 24).

Além desses aspectos, a utilização de filmes em âmbito do Ensino de História pode auxiliar na compreensão de que tudo é/faz parte da História, já que, como bem observou Morettin (2003, p. 13), o "[...] cinema é um testemunho singular de seu tempo [...]". Segundo os autores Nóvoa e Barros, através do cinema é possível "[...] compreender o mundo contemporâneo, tendo em vista que o cinema [...] se transformou em um poderoso agente capaz de agir e interferir na própria história [...]" (NÓVOA; BARROS, 2012, p. 8), servindo como fonte para compreender de que forma o ser humano interpreta ou percebe os acontecimentos/as histórias a sua volta.

Nesse contexto, o filme cinematográfico pode auxiliar no desenvolvimento ou aprimoramento das seguintes habilidades (CORRÊA; GONÇALVES, 2018):

a) prática de novas leituras e interpretação através de recursos audiovisuais;

b) análise crítica de obras cinematográficas;

c) reconhecimento do potencial informativo de recursos fílmicos;

d) reconhecimento das intenções e visões intrínsecas à representação cinematográfica;

e) desenvolvimento do senso crítico voltado aos bens culturais; 
f) discernimento entre o fato e a ficção;

g) identificação de estratégias de pesquisa em fontes audiovisuais;

h) aprimoramento da criatividade e, consequentemente, da escrita.

A seguir, apresentam-se os procedimentos metodológicos que permitiram o desenvolvimento desta pesquisa.

\section{Procedimentos metodológicos}

Este estudo é de cunho quali-quantitativo, o qual se constitui em um método misto. Apresenta, portanto, as especificidades da abordagem quantitativa, que "obtém dados descritivos" através da coleta de dados numéricos, e as características da pesquisa qualitativa, que compreende um conjunto de práticas interpretativas e, portanto, intuitivas que visam à obtenção de dados de cunho textual (BARDIN, 2011, p. 145).

Esta pesquisa é descritiva. A elaboração do estudo compreendeu duas etapas: a bibliográfica, que permitiu conhecer o que já foi escrito sobre o assunto (MARCONI; LAKATOS, 2010), e a documental, cujas fontes foram os blogs e sites administrados por docentes de História de escolas brasileiras. Portanto, as mídias virtuais foram usadas como fontes documentais.

Este estudo teve como corpus de pesquisa as informações referentes à indicação de filmes pelos docentes de História de escolas brasileiras em seus blogs e sites. Nesse sentido, o universo de pesquisa se constituiu nos meios virtuais administrados por professores de História.

A coleta de dados da pesquisa documental compreendeu o período de julho de 2017 a abril de 2018. Tal coleta foi realizada mediante buscas simples no buscador Google por meios virtuais relacionados ao Ensino de História utilizando a seguinte expressão: blogs de professores de História (sem aspas).

Os dados analisados nesse estudo seguiram, inevitavelmente, os critérios impostos pelos próprios resultados obtidos através do buscador Google, que tem indicadores de relevância aplicados às buscas, retornando, em tese, conteúdos significativos. Foram analisados os primeiros 25 blogs ou sites considerados potenciais relevantes para esta pesquisa nas páginas dos resultados do Google. 
A fim de refinar os dados, formulou-se uma série de indicadores próprios para considerar um meio virtual relevante ou não para este estudo (em específico), seguindo as considerações de Tomaél e colaboradores (2001) e de Sales e Almeida (2007), a saber:

a) título ou texto de apresentação do blog ou site relacionando o mesmo ao Ensino de História;

b) administrador do blog ou site com formação em História, atuante na disciplina e em escolas de Educação Básica;

c) blog ou site com relevância para o Ensino de História;

d) blog ou site atualizado (contendo informações do ano de 2017);

e) interface amigável;

f) acesso livre;

g) em língua portuguesa.

A partir da identificação dos meios virtuais, foi feito o reconhecimento de tags ou menus que contemplassem questões voltadas ao uso de recursos midiáticos no ensino-aprendizagem ou à indicação de mídias fílmicas. Dos 25 blogs e sites preliminarmente identificados, seis foram descartados: um por não ser administrado por professor de História; um administrado por docente com formação em História, porém, não lecionando a disciplina na escola que atua (leciona Geografia, Filosofia e Sociologia); um por não ser possível identificar a formação em História e atuação na disciplina; em dois blogs não foi possível identificar se os docentes atuavam na educação básica ou no ensino superior; em um blog não foi possível acessar as informações dos menus e tags pois estavam com links inacessíveis. Mediante o exposto, a busca por informações pertinentes a esta pesquisa foi realizada em 19 meios virtuais.

Os resultados preliminares foram elencados em duas planilhas eletrônicas. A primeira tinha as seguintes categorias, ordenadas a seguir: título do site ou blog; link para acesso; texto de apresentação do blog ou site (a que ele se destina); administrador do blog ou site; contato; cidade/estado de atuação do professor; data da última atualização; tags ou menus relacionadas a indicação de filmes (quando houver). Os dados descritos nesta planilha corresponderam aos 19 meios virtuais que contemplaram os indicadores formulados a partir das considerações de Tomaél e colaboradores (2001) e Sales e Almeida (2007). 
A segunda planilha voltou-se à organização dos filmes indicados pelos docentes e os respectivos assuntos dos mesmos. Através da identificação de tags ou menus referentes à utilização ou indicação do cinema como recurso didático, foi possível reconhecer filmes que podem ser aplicados ao Ensino de História. As buscas foram realizadas dentro dos meios virtuais utilizando os termos pósdefinidos: cinema, filme(s), audiovisual(ais), vídeo(s), material(is) didáticopedagógico(o), ou quaisquer expressões que caracterizassem o uso de mídias fílmicas no ensino. Esta análise foi realizada nos 19 meios virtuais identificados como potenciais para a pesquisa. Mediante este exame, observou-se a indicação de obras cinematográficas em nove blogs ou sites.

Esta segunda planilha contou com as seguintes categorias: título do site ou blog; observações gerais sobre o blog ou site; filmes indicados; data de lançamento do filme; gênero cinematográfico; nacionalidade do filme; tag ou menu (com a indicação do filme); assunto indicado pelo professor atribuído ao filme; informações sobre o filme (comentários, resenhas, roteiro de uso em sala de aula, entre outros). Todas as informações dispostas na planilha foram coletadas nos blogs ou sites investigados. Posteriormente, foi realizada a conferência dessas informações para disponibilizar a listagem final de filmes indicados. Optou-se por utilizar a base Internet Movie Database (IMDb) (AMAZON COMPANY, 1990) para averiguação das informações técnicas em virtude da indicação da Unesco (WILSON et al., 2013), que aponta a IMDb como fonte de informação confiável no âmbito do Cinema. Assim, a denominação do título e a data de publicação das obras cinematográficas, por exemplo, foram corrigidas quando houve necessidade.

As informações coletadas na segunda planilha consistem em características dos filmes, como data de publicação ou lançamento, gênero cinematográfico, nacionalidade de produção, ficha técnica, sinopse, entre outras. Averiguou-se, também, os assuntos históricos atribuídos pelos professores aos filmes indicados, apontando as metodologias de análise de filmes propostas por eles. Além desses dados, foram coletadas informações para auxiliar a correlação das noções teórico-conceituais da media information literacy com as indicações de filmes apresentadas nos blogs e sites investigados. 
A análise dos dados foi realizada pela aplicação do método de Análise de Conteúdo preconizado por Bardin (2011), com enfoque na etapa de categorização e inferência. Formularam-se categorias a priori e a posteriori, as quais foram aplicadas aos dados.

A categorização deu-se em duas situações. A primeira, para possibilitar a organização dos dados, no caso, dos blogs e sites relevantes ou não para este estudo. Nesse contexto, tem-se as seguintes categorias: título do site ou blog; link para acesso; texto de apresentação do blog ou site (a que ele se destina); administrador do blog ou site; contato; cidade/estado de atuação do professor; data da última atualização; tags ou menus relacionados à indicação de filmes; existência ou não de filmes indicados; existência ou não de tema(s)/assunto(s) atribuídos à obra cinematográfica; existência ou não de observações referentes à obra indicada (como usá-la em sala de aula; crítica à abordagem do assunto, resenha, entre outras). Tais categorias foram criadas para permitir a organização primária dos dados coletados no Google. No segundo momento, os dados foram recategorizados. Nessa etapa, foram apontados os filmes apresentados nos meios virtuais e os assuntos atribuídos a eles. Além disso, procurou-se identificar a existência de atividades para sala de aula, resenhas, comentários, críticas à abordagem do assunto histórico, entre outros, atribuídos ao filme.

A etapa de inferência, que consiste basicamente na análise final dos dados coletados (BARDIN, 2011), foi realizada mediante a correlação entre o corpus da pesquisa (informações dos meios virtuais) e a literatura publicada no âmbito da media information literacy.

\section{Resultados e discussões}

Após o reconhecimento dos blogs e sites, a análise voltou-se para a identificação de filmes indicados nos meios virtuais. Dos 19 meios verificados, dez apresentaram indicações de obras cinematográficas distribuídas comercialmente. No entanto, um deles foi desconsiderado para esta pesquisa, pois o menu do blog remetia a verbete da Wikipédia e não listagem própria elaborada pelo professor.

A Tabela 1 ilustra o número total de filmes indicados pelos meios virtuais, somando 420 indicações; desse total, observou-se 362 títulos diferentes. 
Tabela 1 - Indicações de obras cinematográficas por meio virtual Meios virtuais

\begin{tabular}{ll}
\hline Blog de História do $6^{\mathbf{0}}$ e $7^{\mathbf{0}}$ anos & 6 \\
Blog do Professor Tarcivan & 1 \\
Contando Histórias: Professor Heber - Fundamental II - CPBEedu blogs & 31 \\
Ensinar História: por Joelza Ester Domingues & 93 \\
Fatos Históricos: Blog de História - Prof. Edson Cupertino & 8 \\
Histórias & 180 \\
Histosofia: Blog & 7 \\
Professor Ferdinando: Coisas de História & 7 \\
Professor Odair - História & 87 \\
Total de indicações & 420 \\
\hline
\end{tabular}

Fonte: Dados da pesquisa (2018).

A análise deteve-se aos resultados voltados aos aspectos de Competência em Informação e Mídia observados nos blogs e sites investigados. Em consonância com a literatura publicada, buscou-se identificar informações em âmbito das indicações de filmes apresentadas pelos docentes nos meios virtuais que se configuram em dimensões de CoInfo (VITORINO; PIANTOLA, 2011) e em níveis (padrões e indicadores) de CIM (WILSON et al., 2013). Para esclarecimento, elencam-se as características, pré-definidas e pós-definidas, que demonstram a existência desses padrões e indicadores:

a) quanto à Dimensão Técnica, foram observadas menções relacionadas ao acesso, à avaliação e ao uso dos recursos fílmicos;

b) quanto à Dimensão Estética, explorou-se a indicação, propriamente dita, dos recursos fílmicos, além da menção do uso de outras TICs em âmbito educacional;

c) quanto à Dimensão Ética, buscou-se identificar dados referentes à indicação de autoria nas informações postadas nos meios virtuais em âmbito dos recursos fílmicos;

d) quanto à Dimensão Política, foram observadas informações relativas ao potencial democrático e positivo do uso das linguagens fílmicas para fins educacionais, bem como o potencial negativo, voltado à ideia de que há intenções comerciais e ideológicas por trás da produção cinematográfica. 
Cabe salientar que a não existência desses aspectos nas postagens dos blogs e sites não significa incompetência em informação e mídia. Frisa-se essa observação, porque, em algumas postagens divulgadas nos meios virtuais, fica claro que o(a) docente utilizou o filme citado em classe e está retomando algo que já fora discutido em sala de aula. Nesse sentido, algumas informações podem ter sido suprimidas nessas postagens (e discutidas apenas em sala de aula).

No que se refere à Dimensão Técnica, aspectos voltados à escolha (ou localização) das obras cinematográficas não foram expostos com clareza pelos administradores dos meios virtuais. Através dos textos de contextualização apresentados junto às indicações de filmes, pode-se inferir que os recursos fílmicos citados, em maioria, são fruto de escolhas pessoais ou correspondem à indicação de outro(a) profissional da educação, como pode ser visto nos exemplos a seguir:

a) a docente administradora do Blog de História do $6^{\circ}$ e $7^{\circ}$ anos menciona que "[...] a professora Carolina $[\ldots]$ tinha um blog para o sétimo ano, $[\ldots]$ [e] sempre fazia essa postagem para seus alunos [...]" (RODRIGUES, [2017], doc. não paginado) indicando o filme Amistad (1997);

b) a docente administradora do site Ensinar História apontou que a "[...] professora Ana Paula Martins, de São Paulo - SP, sugeriu o curta A Roda (Das Rad) para trabalhar a noção de tempo histórico e tempo geológico." (DOMINGUES, c2015, doc. não paginado).

Ressalta-se, portanto, a interação entre profissionais da educação, o que permite inferir que há compartilhamento de saberes e práticas docentes no que se refere ao uso de filmes com intuito educativo. Para além disso, percebe-se que os próprios docentes utilizam outros blogs como fonte de informação.

Quanto à avaliação e ao uso das obras cinematográficas — também, aspectos da Dimensão Técnica, os meios virtuais Blog do Professor Tarcivan (MONTEIRO, [2017]) e Contando Histórias (c2016) apresentaram atividades específicas aplicadas aos filmes Hotel Ruanda (2004), O menino do pijama listrado (2008) e Tempos modernos (1936). Essas atividades consistem em questionários com perguntas e propostas de resenhas/redações que permitem (ou possibilitam) a interpretação da narrativa do filme e contemplam assuntos curriculares correspondentes às obras cinematográficas. 
Nessa mesma perspectiva, cabe ressaltar duas publicações do site Ensinar História (DOMINGUES, c2015, doc. não paginado): O Cinema como recurso pedagógico no Ensino de História, postada em 30 de setembro de 2017, e Como analisar filmes históricos, postada em 7 de janeiro de 2015. Nas publicações, a docente administradora do site aponta estratégias e passo a passo para escolha, avaliação e utilização de filmes com intento educacional no âmbito do Ensino de História (DOMINGUES, c2015).

No que se refere à Dimensão Estética, é possível afirmar que a indicação, propriamente dita, de filmes como recurso didático-pedagógico já pressupõe a existência dessa competência, ou seja, todos os nove blogs e sites que apontaram recursos fílmicos para trabalhar assuntos históricos, ou apenas os indicaram, contemplam a referida dimensão de CoInfo, a qual presume a utilização de um "[...] amplo leque de 'textos' de mídia [...] através de diversos formatos [...]" (WILSON et al., 2013, p. 33) com intuito de expressar as ideias e saberes preexistentes do indivíduo.

A Dimensão Ética, por sua vez, se refere ao apontamento de fontes referenciais. Os meios virtuais Blog de História do $6^{\circ}$ e $7^{\circ}$ anos (RODRIGUES, [2017]), Fatos Históricos (CUPERTINO, [2017]) e Professor Ferdinando ([2017]) apontaram as fontes das quais obtiveram as sinopses dos filmes citados por eles. Destaca-se a utilização dos sites AdoroCinema (2000) e Omelete (2000) pelos docentes que, mesmo se tratando de fontes informais, são amplamente conhecidas em redes sociais, por exemplo. O site Ensinar História (DOMINGUES, c2015) utilizou, em sua maioria, as sinopses do catálogo da Cinemateca Brasileira ([2020]).

Além das dimensões citadas acima, cabe expor alguns aspectos que se referem à compreensão da linguagem cinematográfica, dos seus propósitos e de suas intencionalidades. Nesse sentido, foram observados os seguintes trechos, provenientes dos textos de contextualização apresentados junto às indicações de filmes, que contemplam a Dimensão Política da CoInfo, a saber:

a) sobre o título A queda! As últimas horas de Hitler (2004), o blog Histosofia (c2010) atribui ao filme a característica de histórico e salienta que utiliza o termo entre aspas porque não se deve confundir “" [...] os fatos 


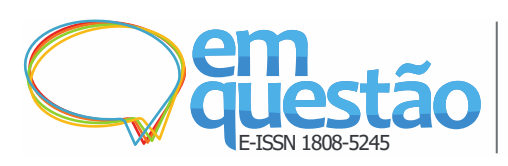

Competência em Informação e Mídia no Ensino de

História: observações acerca de indicações de obras

cinematográficas em meios virtuais

Sabrina Simões Corrêa, Renata Braz Gonçalves

históricos com as versões dos mesmos apresentados pelas lentes do cinema." (HISTOSOFIA..., c2010, doc. não paginado);

b) o site Ensinar História menciona que um filme de tema histórico

[...] é uma representação artística da História e não um documento histórico. Como recurso didático ele é útil para promover debates pós-exibição e confrontar o filme com o tema estudado em sala de aula. [Além disso, aponta que não é exagero] [...] afirmar que, o grande público, hoje, tem mais acesso à História mostrada nas telas do cinema do que pela leitura de livros e pelo ensino nas escolas. [Nesse sentido][...] é importante refletir sobre que História o cinema conta, que visão do passado ele transmite. (DOMINGUES, c2015, doc. não paginado).

c) no texto de contextualização sobre o filme Chernobyl (2012), o blog Fatos Históricos aponta que "[...] não se estuda história vendo filme algum" (CUPERTINO, [2017], doc. não paginado). Além disso, o cinema “[...] é uma arte provocativa sim, mas observando-se que ela é voltada para a diversão e, por isso, não tem nenhuma obrigatoriedade em seguir dados históricos.” (CUPERTINO, [2017], doc. não paginado);

d) quanto ao filme Deuses do Egito (2016), o blog supracitado também salienta que um “[...] filme nunca substituirá a análise histórica em sua profundidade feita pelo professor (ou historiador)." (CUPERTINO, [2017], doc. não paginado). Sobre a utilização didática desse e de outros filmes, em geral, o docente considera “[...] sempre bem-vinda qualquer produção que torne possível, por meio de narrativa ficcional e de aventura, apresentar ao educando alguns aspectos que foram ou que serão abordados [...]" (CUPERTINO, [2017], doc. não paginado) em sala de aula, e mais

1. O cinema nunca teve como objetivo ensinar história. Isso é tarefa de outros lugares e profissionais.

2. Considero toda e qualquer produção contemporânea bem-vinda [sic] no sentido de fornecer ao aluno instrumentos para se apoderar de um olhar crítico sobre os produtos de consumo que o cercam. (CUPERTINO, [2017], doc. não paginado).

c) Professor Ferdinando ([2017]), ao mencionar o filme Cruzada (2005), alerta a turma ao indicar que, ao assistir ao filme, "[...] considere o contexto histórico, os valores e as visões de mundo da equipe produtora 
do mesmo e não como uma verdade histórica pura." (PROFESSOR... ([2017], doc. não paginado).

Mediante as informações apresentadas acima, é possível afirmar que os meios virtuais investigados contemplam indicadores e padrões de Competência em Informação e Mídia, uma vez que fazem o uso efetivo e ético de informações voltadas à utilização de recursos fílmicos para fins educativos.

Tal afirmação se dá em virtude do potencial informativo das postagens apresentadas pelos meios virtuais que relacionam os filmes com os assuntos curriculares e com temas diários, também observados em outros meios de comunicação, a exemplo da televisão. Correlacionar informações já existentes com novas informações é a característica de um indivíduo competente em informação, como mencionado na revisão de literatura.

\section{Considerações finais}

O desenvolvimento deste estudo possibilitou compreender a importância do uso efetivo e ético de recursos midiáticos, em especial, das mídias fílmicas. A relação entre os dados coletados na pesquisa documental (efetuada nos blogs e sites) e as considerações apontadas pelos teóricos corroborou com a afirmativa de que as TICs estão cada vez mais presentes nos processos de ensino-aprendizagem; devem ser utilizadas de maneira consciente e perspicaz; devem ser 'consumidas' além dos propósitos originais e exploradas no seu máximo para que cumpram, de maneira positiva, seu papel no ensino (papel este que vem sendo demonstrado através de pesquisas como esta).

Entretanto, para que os novos propósitos incumbidos às mídias sejam exequíveis e obtenham sucesso, é necessário que a atenção se dirija às consequências que a utilização desses meios pode acarretar. Cabe, portanto, compreender que, por trás do uso de um recurso midiático, há a necessidade imperativa de preparar os indivíduos para sua utilização - tanto mestres quanto aprendizes. Importa, ainda, compreender que esses saberes são ilimitados, pois o uso de recursos midiáticos pressupõe o uso de tecnologias - e, a cada dia, inovações são criadas e disponibilizadas. Atualizar-se faz parte (ou deve fazer parte) do cotidiano de qualquer pessoa, principalmente daquelas que participam dos processos de ensino-aprendizagem dos outros. 
As iniciativas propostas pela corrente da media information literacy são essenciais para a consolidação das noções apresentadas acima, que vão além do simples uso de recursos midiáticos e pressupõem a compreensão, a crítica e a ética inerentes à utilização. Percebeu-se que a preocupação em exercitar e tornar possível o uso de mídias é partilhada por profissionais da informação e da educação. $\mathrm{O}$ entrelace entre o papel educativo de bibliotecários e as noções construtivistas da Educação impulsionaram o desenvolvimento de aportes teórico-conceituais e práticas no âmbito do uso da informação. Agregado ao avanço tecnológico, principalmente à popularização das TICs, houve o alcance de estratégias para uso das mídias não somente nos espaços formais de ensino, mas também, e não menos importante, nos espaços informais de aprendizagem.

Cada vez mais as TICs estão sendo inseridas nas práticas docentes. A criação de blogs e sites, por exemplo, para apoiar ou retomar conteúdos que antes eram apenas discutidos (ou pouco discutidos) em espaços informais de ensino e corrobora esta afirmação. Importa mencionar, também, que a distância entre gerações - como salientaram Tufte e Christensen (2009), está desaparecendo. Isso permite inferir que profissionais da educação, muito embora esquecidos e desvalorizados por um sistema de ensino depreciado, estão saindo de suas zonas de conforto para buscar o além - e possibilitar que a aprendizagem seja desenvolvida de maneira lúdica e atual. Tal percepção se intensifica neste momento, quando docentes e demais profissionais da educação têm repensado suas metodologias e ações de ensino para tornarem viáveis ao momento de distanciamento social, decorrente da pandemia do Covid-19, que ocasionou na migração (sem aviso antecipado) da sala de aula presencial para os ambientes virtuais de aprendizagem.

Contudo, em um contexto de normalidade, observa-se que a criação/ utilização de meios virtuais como apêndice extraclasse permite que os estudantes tenham contato com esses recursos de modo a interagir a partir dele (compartilhando e criando conteúdos), e não apenas exercer a função passiva de leitor. Além disso, cria-se uma interação entre professor(a)/aluno(a); uma conexão, antes impossibilitada (ou pouco desenvolvida) pelos processos de ensino fundamentados na memorização e na verdade absoluta trazida pelo discurso do professor(a) ou pelo livro didático. 
Além disso, o uso de mídias, de forma geral, facilita o desenvolvimento e aprimoramento de habilidades e competências informacionais e midiáticas. Dentre elas, destacam-se: a prática de novas leituras e interpretações; o reconhecimento do potencial informativo de recursos midiáticos; o reconhecimento das intenções e visões intrínsecas às mídias; o desenvolvimento do senso crítico voltado aos bens culturais e de consumo; o discernimento entre o fato e a ficção, a verdade e a mentira ou as verdades/versões; a identificação de estratégias de pesquisa em fontes midiáticas; o aprimoramento da criatividade e, consequentemente, da escrita através do uso de recursos midiáticos; dentre outras.

Quanto aos recursos fílmicos, o aprimoramento e desenvolvimento de habilidades e competências também é visível. Além dos aspectos citados no parágrafo anterior, o uso efetivo e ético de filmes possibilita: o reconhecimento do potencial informativo desses recursos; o reconhecimento das intenções e visões intrínsecas à narrativa cinematográfica; a noção de diferentes visões e versões da História; a identificação de estratégias de pesquisa em fontes audiovisuais; o aprimoramento da criatividade e, consequentemente, da escrita, pois a narrativa cinematográfica possibilita o enriquecimento do imaginário; dentre outras.

Através da análise efetuada nos meios virtuais, foi possível identificar o uso de fontes informais (não científicas) aplicadas ao ensino. Relembra-se a utilização de outros blogs e sites para fomentar ou dispor informações sobre os filmes indicados - AdoroCinema (2000) e Omelete (2000) são alguns dos exemplos (fora a utilização da Wikipédia, também observada nos meios virtuais investigados). Tal prática não deve ser sentenciada ao desprezo, uma vez que isso indica a aproximação, pelos docentes, da cultura informativa dos(as) estudantes. É importante esclarecer que o uso de fontes informais não significa o uso de informações suspeitas (ou falsas); apenas pressupõe a necessidade de que o(a) docente, ao fazer o uso desses meios informacionais, conheça estratégias de reconhecimento e diferenciação entre conteúdos confiáveis e não confiáveis.

Mediante as observações conferidas nos meios virtuais, é pertinente afirmar que o uso de blogs - pelos(as) docentes, propicia o entendimento, por parte dos(as) estudantes, de que há outros espaços que possibilitam a troca e o 
compartilhamento de saberes. Com efeito, permite que estudantes reconheçam o potencial informativo de outros suportes - não apenas dos materiais impressos.

É fundamental haver aprimoramento e desenvolvimento de habilidades e competências no âmbito da informação e da mídia, uma vez que, o acesso a recursos não convencionais (no ensino, no cotidiano) exige que o(a) aluno(a) e o(a) professor(a) saibam reconhecer a confiabilidade de fontes de informação nos diversos formatos (principalmente, quando essas fontes estão disponíveis na Internet). Nesse contexto, o bibliotecário se insere como agente mediador na promoção de estratégias para o uso efetivo e ético da informação disponível em diferentes suportes.

\section{Referências}

ADOROCINEMA. Brasil, 2000. Disponível em: http://www.adorocinema.com/. Acesso em: 2 jul. 2020.

AMAZON COMPANY. Internet Movie Database. Reino Unido: [s. n.], 1990. Disponível em: https://www.imdb.com/. Acesso em: 2 jul. 2020.

AMISTAD. Direção: Steven Spielberg. Produção: Debbie Allen et al. Estados Unidos da América: DreamWorks, 1997. 1 DVD (155 min) color.

A QUEDA! As últimas horas de Hitler. Direção: Oliver Hirschbiegel. Produção: Bernd Eichinger et al. Alemanha: Constantin Film, 2004. 1 DVD (156 min) son., color.

BARDIN, Laurence. Análise de conteúdo. São Paulo: Edições 70, 2011.

CARVALHO, Lívia Ferreira de; GASQUE, Kelley Cristine Gonçalves Dias. Formação continuada de professores e bibliotecários para o letramento informacional: a contribuição da educação a distância. TransInformação, Campinas, v. 30, n. 1, p. 107-119, 2018.

CHERNOBYL. Direção: Bradley Parker. Estados Unidos da América: Alcon Entertainment, 2012. 1 DVD (89 min) son., color.

CINEMATECA BRASILEIRA. Arquivos e coleções. São Paulo: Cinemateca Brasileira, [2020]. Disponível em: http://bases.cinemateca.gov.br/page.php?id=223. Acesso em: 2 jul. 2020.

CONTANDO Histórias. [S. l.], c2016.

CORRÊA, Sabrina Simões; GONÇALVES, Renata Braz. Recursos midiáticos no Ensino de História: desenvolvimento de competências em informação e 
mídia. In: ENCONTRO INTERNACIONAL FRONTEIRAS E

IDENTIDADES, 4., 2018, Pelotas. Anais [...]. Pelotas: UFPEL, 2018. p. 157168.

CRUZADA. Direção: Ridley Scott. Produção: Ridley Scott et al. Reino Unido: Twentieth Century Fox, 2005. 1 DVD (145 min) son., color.

CUPERTINO, Edson Ribeiro. Fatos históricos: blog de História. [S. l.], [2017].

DEUSES do Egito. Direção: Alex Proyas. Produção: Basil Iwanyk et al. Estados Unidos da América: Pyramania, 2016. 1 DVD (127 min) son., color.

DOMINGUES, Joelza Ester. Ensinar História por Joelza Ester Domingues. [S. l.]: Criativito, c2015.

DUDZIAK, Elisabeth Adriana; BELLUZZO, Regina Célia Baptista. Educação, informação e tecnologia na sociedade contemporânea: diferenciais à inovação?

Revista Brasileira de Biblioteconomia e Documentação, São Paulo, v. 4, n. 2, p. 44-51, 2008.

GRIZZLE, Alton et al. Alfabetização midiática e informacional: diretrizes para a formulação de políticas e estratégias. Brasília: UNESCO, 2016.

HISTOSOFIA: blog. [S. l.], c2010.

HOTEL Ruanda. Direção: Terry George. Produção: Sam Bhembe et al. Reino Unido: United Artists, 2004. 1 DVD (121 min), son., color.

LOSSO, Claudia Regina Castellano; CRISTIANO, Marta Adriana da Silva; LUZ FILHO, Silvio Serafim da. Edublogs: a construção e a disseminação do conhecimento de forma colaborativa e cooperativa. In: COSTA, Edemir; RIBAS, Júlio César da Costa; LUZ FILHO, Silvio Serafim da (org.). Mídia, educação e subjetividade: disseminando o conhecimento. Florianópolis: Tribo da Ilha, 2011. p. 43-63.

MARCO de avaliação global da Alfabetização Midiática e Informacional (AMI): disposição e competências do país. Brasília: UNESCO, 2016.

MARCONI, Marina de Andrade; LAKATOS, Eva Maria. Fundamentos de metodologia científica. 7. ed. São Paulo: Atlas, 2010.

MONTEIRO, Tarcivan. Blog do professor Tarcivan. Paraíba: Blogger, [2017].

MORETTIN, Eduardo Victorio. O cinema como fonte histórica na obra de Marc Ferro. História: questões \& debates, Curitiba, n. 38, p. 11-42, 2003.

NAPOLITANO, Marcos. Como usar o cinema em sala de aula. 5. ed. São Paulo: Contexto, 2015. 
NÓVOA, Jorge; BARROS, José D’Assunção (org.). Cinema-História: teoria e representações sociais no cinema. 3. ed. Rio de Janeiro: Apicuri, 2012.

OMELETE. Brasil, 2000. Disponível em: https://www.omelete.com.br/. Acesso em: 2 jul. 2020.

O MENINO do pijama listrado. Direção: Mark Herman. Produção: Mark Herman et al. Reino Unido: Miramax, 2008. 1 DVD (94 min), son., color.

PROFESSOR Ferdinando: coisas de História. São José do Rio Preto, [2017].

RODRIGUES, Alessandra Rizzo. Blog de História do $6^{\mathbf{0}}$ e $7^{\mathbf{0}}$ anos. Rio de Janeiro, [2017].

SALES, Rodrigo de; ALMEIDA, Patrícia Pinheiro de. Avaliação de fontes de informação na internet: avaliando o site do NUPILL/UFSC. Revista Digital de Biblioteconomia e Ciência da Informação, Campinas, v. 4, n. 2, p. 67-87, 2007.

SILVA, Ana Rita Santiago da. A formação de leitores: da leitura da palavra à leitura do mundo. Revista da FAEEBA: educação e contemporaneidade, Salvador, v. 13, n. 21, p. 173-182, 2004.

TEMPOS modernos. Direção: Charles Chaplin. Produção: Charlie Chaplin. Estados Unidos da América: Charles Chaplin Productions, 1936. 1 DVD (87 $\min ) \mathrm{p} \& \mathrm{~b}$.

TOMAÉL, Maria Inês et al. Avaliação de fontes de informação na internet: critérios de qualidade. Informação e Sociedade: estudos, João Pessoa, v. 11, n. 2, p. 13-35, 2001.

TUFTE, Birgitte; CHRISTENSEN, Ole. Mídia-educação: entre a teoria e a prática. Perspectiva, Florianópolis, v. 27, n. 1, p. 97-118, 2009.

UNESCO. Padrões de competência em TIC para professores: diretrizes de implementação, versão 1.0. Paris: UNESCO, 2009.

VITORINO, Elizete Vieira; PIANTOLA, Daniela. Dimensões da competência informacional. Ciência da Informação, Brasília, v. 40, n. 1, p. 99-110, 2011.

WILSON, Carolyn et al. Alfabetização midiática e informacional: currículo para formação de professores. Brasília: UNESCO, 2013.

ZANCHETTA JUNIOR, Juvenal. O difícil diálogo entre escola e mídia. Educação e Pesquisa, São Paulo, v. 43, n. 4, p. 1055-1071, 2017. 


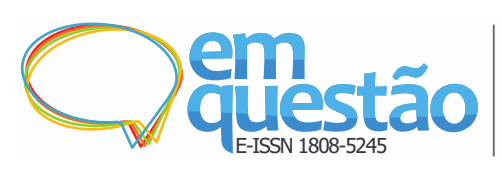

Competência em Informação e Mídia no Ensino de História: observações acerca de indicações de obras cinematográficas em meios virtuais Sabrina Simões Corrêa, Renata Braz Gonçalves

\title{
Media Information Literacy in the Teaching of History: observations about the indication of cinematographic works in virtual media
}

\begin{abstract}
The present research aimed to relate data collected in blogs and websites administered by history teachers of basic education with the theoreticalconceptual assumptions of media information literacy in order to discuss the approach given to cinematographic resources indicated in these virtual media for purposes didactic-pedagogical. As for the methodology, this research is characterized as a descriptive study of qualitative and quantitative nature. The study was elaborated through bibliographic research and documentary research, whose sources were virtual media. The analysis was based on the Content Analysis method. With regard to the results, the research observed 25 virtual media, of which nine presented indications of cinematographic works, totaling 362 distinct films. The information provided by teachers in virtual media allowed the identification of aspects related to media information literacy, among them: mentions related to access, evaluation and use of film resources; note of data referring to the indication of authorship in the information posted on virtual media; observation of information that admitted the democratic and positive potential of the use of film languages for educational purposes, as well as the negative potential, aimed at the idea that there are commercial and ideological intentions behind film production. We conclude that it is essential to improve and develop information and media skills and competences, since access to 'unconventional' resources requires new skills from individuals. In this context, the librarian is inserted as a mediating agent in the promotion of strategies for the effective and ethical use of information.
\end{abstract}

Keywords: Media Information Literacy. History teaching. Media in Education. Cinema.

Recebido: 02/07/2020

Aceito: $10 / 10 / 2020$

Declaração de autoria

Concepção e elaboração do estudo:

Coleta de dados:

Análise e interpretação de dados

Redação:

Revisão crítica do manuscrito:

Como citar

CORRÊA, Sabrina Simões; GONÇALVES, Renata Braz. Competência em Informação e Mídia no Ensino de História: observações acerca de indicações de obras cinematográficas em meios virtuais. Em Questão, Porto Alegre, v. 27, n. 2, p. 370-391, abr./jun. 2021.

Doi: http://dx.doi.org/10.19132/1808-5245272.370-391 
Competência em Informação e Mídia no Ensino de História: observações acerca de indicações de obras cinematográficas em meios virtuais

Sabrina Simões Corrêa, Renata Braz Gonçalves

${ }^{1}$ POZO, J. I. Sociedade da aprendizagem e o desafio de converter informação em conhecimento. Pátio, [ $s$. l.], v. 8, p. 34-36, 2004. Apud Carvalho e Gasque (2018). 